\title{
The fate of the abdominal aorta after endovascular treatment in chronic Debakey IIIb aneurysm
}

Tae-Hoon Kim, MD, ${ }^{\text {a }}$ Suk-Won Song, MD, PhD, ${ }^{a}$ Kwang-Hun Lee, MD, PhD, ${ }^{b}$ Min-Young Baek, RN, ${ }^{a}$ Kyung-Jong Yoo, $\mathrm{MD}, \mathrm{PhD},{ }^{c}$ and Hye Sun Lee, $\mathrm{PhD}^{\mathrm{d}}$

\section{ABSTRACT}

Objectives: We sought to identify the risk factors for abdominal aortic remodeling after thoracic endovascular aortic repair in patients with chronic DeBakey IIIb aneurysm.

Methods: From 2012 to 2016, 70 patients underwent thoracic endovascular aortic repair for chronic DeBakey IIIb aneurysm. The abdominal aortic diameter was measured at 3 different levels (celiac trunk, renal artery, and infrarenal aorta). Abdominal aorta status was classified as expansion or stable. Expansion status was assigned when the abdominal aortic diameter was increased over $5 \mathrm{~mm}$ at least 1 level. Otherwise, it was classified as stable status. Forty-six of 70 patients underwent more than 2 postoperative imaging studies. In those patients $(n=46)$, abdominal aortic volume was measured from celiac trunk to inferior mesenteric artery. A linear mixed-effect model was used to analyze the overall fate of abdominal aortic volume.

Results: No in-hospital mortality occurred. The mean follow-up and imaging follow-up duration were 26 and 17 months, respectively. Sixty-one patients $(87.1 \%)$ demonstrated thoracic false-lumen thrombosis. Although false-lumen thrombosis was achieved, 15 patients $(24.6 \%)$ demonstrated the expansion status. In volumetric analysis, the total abdominal aortic volume was increasing over time $\left(0.603 \mathrm{~cm}^{3} / \mathrm{mo} ; P<.001\right)$ and the residual intima tears were identified as an independent anatomic risk factor for an enlarged abdominal aorta.

Conclusions: An enlarged abdominal aorta in chronic DeBakey IIIb aneurysm can be frequently recognized even after successful endovascular treatment. The residual intima tears were the only identified risk factor for change in a dissected abdominal aneurysm. We suggest careful abdominal aorta evaluation and additional procedures on the false lumen if necessary. (J Thorac Cardiovasc Surg 2018;156:27-35)

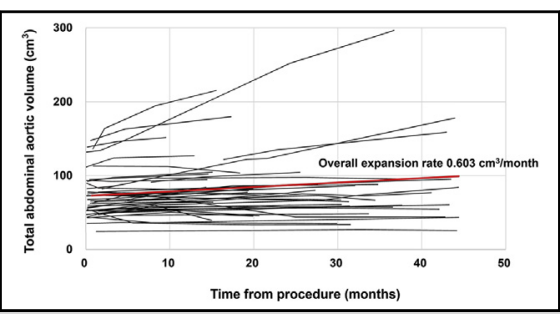

Spaghetti plot showing changes of total abdominal aortic volume over time $(n=46)$.

\section{Central Message}

After successful TEVAR, abdominal aortic expansion in chronic DeBakey IIIb aneurysm may be observed. Careful postprocedure evaluation of the abdominal aorta is imperative.

\section{Perspective}

Knowing the fate of a dissected abdominal aneurysm is very important to improve the outcome of endovascular management in patients with chronic DeBakey IIIb aneurysm. The abdominal aorta is not stable after successful TEVAR; therefore, TEVAR and additional thoracoabdominal false lumen procedures will improve the outcome of endovascular treatment.

See Editorial Commentary page 36.
From the ${ }^{\mathrm{a}}$ Departments of Cardiovascular Surgery and ${ }^{\mathrm{b}}$ Interventional Radiology, Gangnam Severance Hospital, ${ }^{\mathrm{c}}$ Department of Cardiovascular Surgery, Yonsei Cardiovascular Hospital, Severance Hospital, and ${ }^{\mathrm{d}}$ Biostatistics Collaboration Unit, Yonsei University College of Medicine, Seoul, Republic of Korea.

Supported by a Yonsei University College of Medicine 2014 faculty research grant (No. 6-2014-0129)

Received for publication May 1, 2017; revisions received Feb 10, 2018; accepted for publication March 2, 2018.

Read at the 97th Annual Meeting of The American Association for Thoracic Surgery, Boston, Massachusetts, April 29-May 3, 2017.

Received for publication May 1, 2017; revisions received Feb 10, 2018; accepted for publication March 2, 2018; available ahead of print April 27, 2018

Address for reprints: Suk-Won Song, MD, PhD, Department of Cardiovascular Surgery, Gangnam Severance Hospital, Yonsei University College of Medicine, 211 Enoju-ro, Gangnam-gu, Seoul 06273, Republic of Korea (E-mail: sevraphd@yuhs.ac).

$0022-5223 / \$ 36.00$

Copyright $\odot 2018$ by The American Association for Thoracic Surgery

https://doi.org/10.1016/j.jtcvs.2018.03.118
Although thoracic endovascular aortic repair (TEVAR) is commonly used for chronic DeBakey type IIIb (CDIIIb) aneurysms, aortic remodeling outcomes after TEVAR in CDIIIb aneurysms have been unsatisfactory. ${ }^{1-3}$ False lumen (FL) thrombosis after TEVAR is achieved more frequently in chronic DeBakey type IIIa or acute dissection. However, for CDIIIb, this rate ranges from $30 \%$ to $60 \%{ }^{4-7}$ Full coverage of the descending thoracic

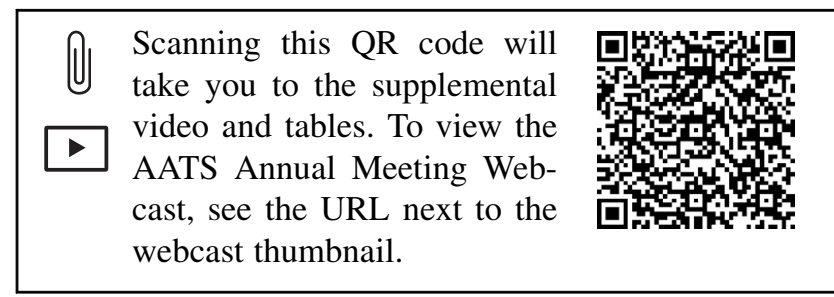




$$
\begin{aligned}
& \text { Abbreviations and Acronyms } \\
& \text { CDIIIb = chronic DeBakey IIIb } \\
& \text { CT = computed tomography } \\
& \text { DTA }=\text { descending thoracic aorta } \\
& \mathrm{FL} \quad=\text { false lumen } \\
& \text { FLP }=\text { false lumen procedure } \\
& \text { LMM = linear mixed model } \\
& \text { OAR }=\text { open aortic repair } \\
& \text { TEVAR }=\text { thoracic endovascular aortic repair } \\
& \text { TFT = thoracic false lumen thrombosis } \\
& \mathrm{TL}=\text { true lumen }
\end{aligned}
$$

aorta (DTA) with a stent graft and an additional FL procedure (FLP) is a strategy employed in our institution, and a thoracic FL thrombosis (TFT) rate up to $80 \%$ has been achieved.

In addition to the unsatisfactory aortic remodeling within the thoracic aorta, the fate of residual abdominal aortic dissection after TEVAR is another challenge in patients with CDIIIb. Moreover, the fate of residual abdominal aortic dissection in these patients is controversial. In the Investigation of Stent Grafts in Aortic Dissection With Extended Length of Follow-up (INSTEAD-XL) trial, patients in the TEVAR arm developed, on average, a diameter decrease of the descending thoracic aorta at the hiatus level (distal to the stent graft) at 5-year follow-up. ${ }^{6}$ In contrast to the INSTEAD-XL trial results, Weber and colleagues ${ }^{8}$ reported that $88.9 \%$ of patients demonstrated abdominal expansion. To optimize the follow-up strategy and outcome of endovascular treatment in patients with CDIIIb aneurysm, identifying the fate of residual abdominal aortic dissection is important. The aims of this study were to determine the frequency of abdominal aortic dissection diameter expansion, to analyze the relationship between abdominal aortic volume expansion and potential influencing factors, and we were specifically interested in whether TFT, FLP, or other aortic features were related to the abdominal aortic volume expansion.

\section{METHODS \\ Patient Population and Data Collection}

This study was approved by the institutional review board of Gangnam Severance Hospital, Yonsei University College of Medicine (No. 3-2012-0259). The need for individual patient consent was waived. A retrospective review of the Gangnam Endovascular Aortic Registry identified 82 patients who underwent endovascular treatments for CDIIIb aneurysms between 2012 and 2016. Patients without a stent graft or with CDIIIb ending above a renal artery origin were excluded. Thus, 70 patients were enrolled for this study (Figure 1). Chronic aortic dissections were defined as those persisting for longer than 3 months after the diagnosis of acute aortic dissection. ${ }^{9}$ Spinal cord ischemia was defined as any new lower extremity motor and/or sensory deficit, not attributable to intracranial pathologic features, peripheral neuropathy, or neuropraxia. Demographic characteristics, comorbidities, procedure-related details, and complications were collected from medical records. Stroke was defined as any neurologic deficit lasting $>24$ hours that was confirmed by imaging and documented by a neurologist. ${ }^{10}$

\section{Indication and Treatment Method}

TEVAR is the preferred treatment at our institution for CDIIIb aneurysms with suitable anatomy. Indications for TEVAR include newly developed aneurysms, intractable back pain, and aneurysmal degeneration (maximal thoracic aneurysm diameter $>55 \mathrm{~mm}$ or a documented growth rate of $5 \mathrm{~mm}$ in 6 months, as observed in serial computed tomography $[\mathrm{CT}]$ angiograms). In our institution, the aim of TEVAR in CDIIIb patients is to cover the thoracic aorta length as much as possible. Indications for additional FLP include patent FL or a lack of TFT in the descending thoracic aorta at 6 months after initial TEVAR. FLP was performed with commercial materials such as the Amplatzer vascular plug (AGA Medical, Golden Valley, Minn), Nester coil (Cook Medical Inc, Bloomington, Ind), and embolization glue ( $33 \% \mathrm{~N}$-butyl cyanoacrylate mixed with lipiodol), and these materials are inserted into the FL to block retrograde FL flow via intimal tears, visceral branches, or intercostal arteries. A Viabahn stent graft (W.L. Gore \& associates, Flagstaff, Ariz) was also inserted into the visceral branch to block retrograde flow via intima tears within the visceral branches (Video 1).

We performed simultaneous TEVAR and FLP when the FL was not excessively large, in which case the materials used for occlusion would be insufficient, and when the physician believed that unfavorable aortic remodeling was likely because of multiple reentries below the celiac axis, visceral reentries, or intercostal arteries from the FL.

\section{Degree of FL Thrombosis}

The degree of FL thrombosis was analyzed using precontrast, arterial, and delayed-phase postoperative CT angiograms. After the procedures (TEVAR or FLP) were completed, the degree of FL thrombosis was evaluated with delayed-phase CT angiograms and classified as either thoracic FL partial thrombosis if both flow and thrombi were present or as TFT if no flow was observed. The definition of FL thrombosis after endovascular aortic repair varies considerably across studies. ${ }^{4-6}$ We defined TFT as FL thrombosis within the thoracic aorta (thoracic aorta above the diaphragmatic crus on CT angiogram axial view) or down to the distal end of the stent.

\section{Remodeling Analysis}

We measured the diameter of the abdominal aorta at the origin of the celiac artery, renal artery, and the largest site of the infrarenal abdominal aorta. Aortic diameter expansion was defined as a $>5 \mathrm{~mm}$ increase of total aortic diameter. Abdominal aorta status was classified as expansion or stable. Expansion status was defined when the abdominal aortic diameter on the latest CT scan was increased more than $5 \mathrm{~mm}$ (aortic diameter expansion) at 1 level at least. Otherwise, it was classified as stable status. One patient underwent open aortic repair (OAR) after TEVAR. In this patient, the imaging studies until the OAR were evaluated. For comprehensive and precise assessment of the overall fate of abdominal aortic dissection, the authors measured abdominal aortic volume in 46 patients who had more than 2 postoperative imaging studies. The total abdominal aortic volume was defined as volume from celiac trunk to inferior mesenteric artery. True lumen (TL) and FL volume were also measured from celiac trunk to inferior mesenteric artery. Postoperative CT scans were performed during the arterial phase and with delayed-contrast imaging to assess the presence of endoleaks and FL patency before discharge. CT scans were performed at 1,6 , and 12 months after the procedure, and yearly thereafter. ${ }^{10,11}$

\section{Statistical Analysis}

Categorical variables were summarized using frequencies and percentages and compared by Fisher exact test or $\chi^{2}$ test. Continuous 


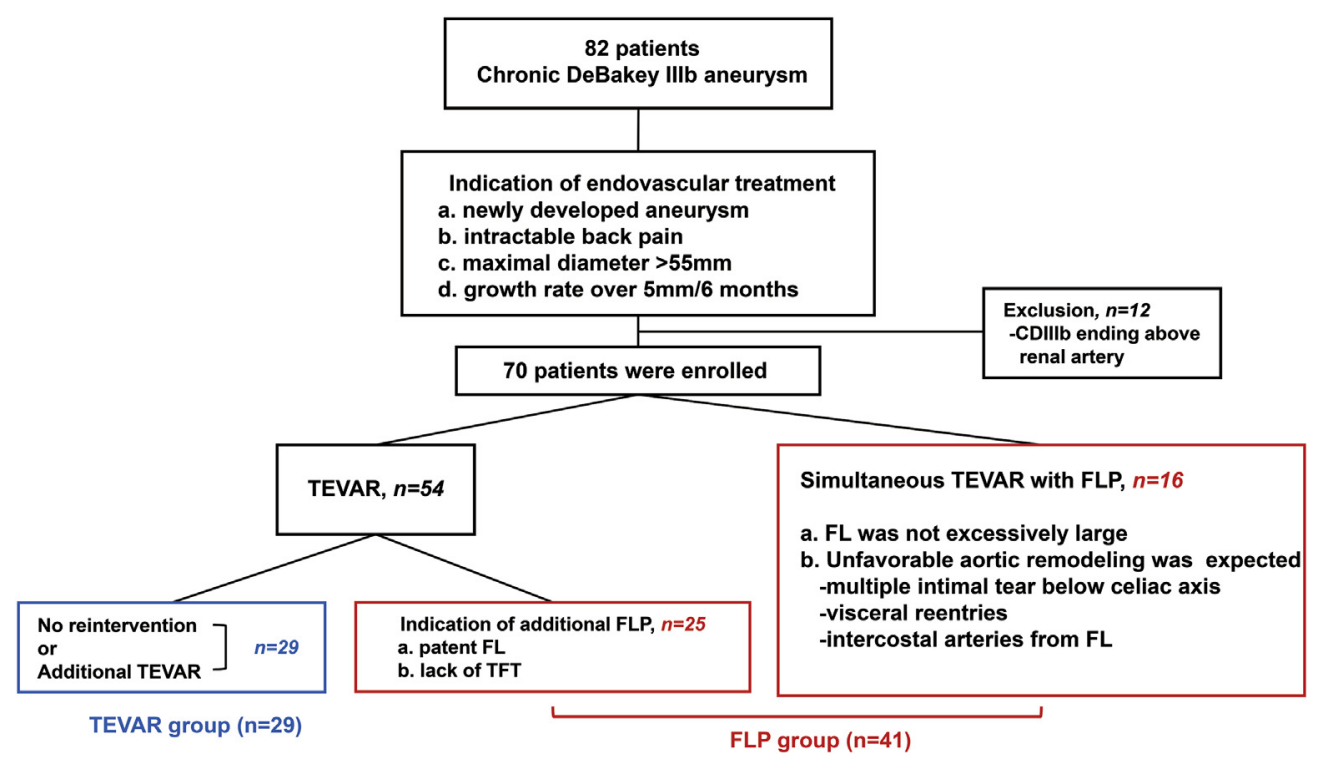

FIGURE 1. Treatment algorithm and study design. CDIIIb, Chronic DeBakey IIIb aneurysm; TEVAR, thoracic endovascular aortic repair; FLP, false lumen procedure; $F L$, false lumen; $T F T$, thoracic false lumen thrombosis.

variables were analyzed using the mean \pm standard deviation with median and interquartile range (IQR) and compared by independent $t$ test or Mann-Whitney $U$ test. Kolmogorov-Smirnov test was used for testing for normality of the distribution. A subgroup analysis using a linear mixed-effects model (LMM) was conducted to analyze the overall fate of abdominal aortic, TL, and FL volume in 46 patients who had more than 2 postoperative imaging studies. A multivariable LMM was built with the anatomy and procedure variables that showed significance to the total abdominal aortic, TL, and FL volume in univariable models, defining a significance level of 0.05 . Significance of the association with total abdominal aortic, TL, and FL volume was demonstrated by a significant

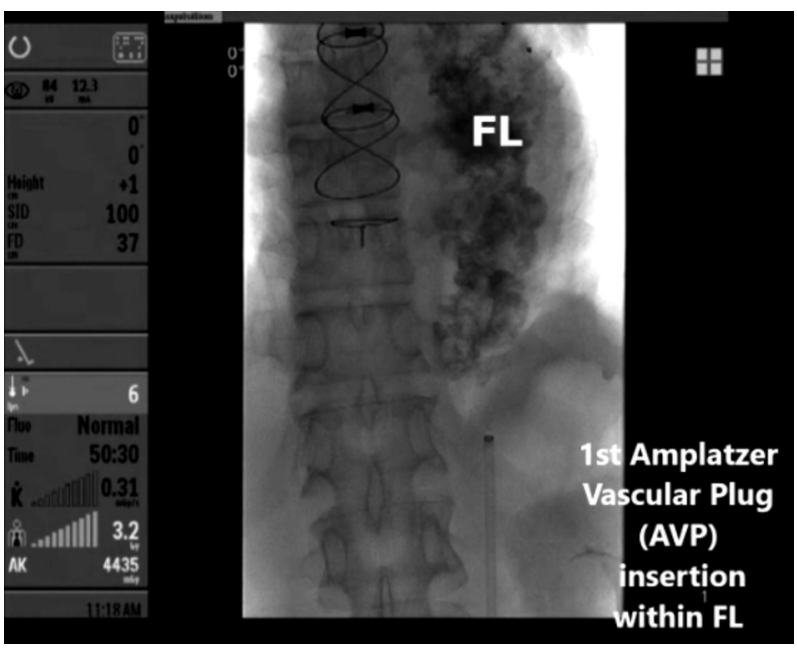

VIDEO 1. False lumen procedure. Nester Coil (Cook Medical Inc, Bloomington, Ind) insertion, Viabahn Stent Graft (W.L. Gore \& Associates, Flagstaff, Ariz) insertion, Amplatzer Vascular Plug (AGA Medical, Golden Valley, Minn), and embolization glue (33\% N-butyl cyanoacrylate mixed with lipiodol) insertion are described. Video available at: https://www.jtcvs.org/article/S0022-5223(18)30901-2/fulltext. interaction with time of a given variable. Subject effect was considered random effect. A model with random intercept and slope was suggested and the covariance structure was assumed as the unstructured component.

Statistical analyses were performed using SPSS for Windows version 22.0 (IBM-SPSS Inc, Armonk, NY) and SAS version 9.2 (SAS Intitute Inc, Cary, NC).

\section{RESULTS}

\section{Patient Demographic Characteristics}

From 2012 to 2016, 70 patients with CDIIIb aneurysm underwent TEVAR at Gangnam Severance Hospital. The overall mean age was $54.8 \pm 11.6$ years (median, 55.0 years; IQR, 46.0-64.0 years). Approximately $75 \%$ of patients in the overall cohort were men. Thirty-four patients $(48.6 \%)$ had CDIIIb aneurysms and 36 patients $(51.4 \%)$ had residual CDIIIb aneurysms after initial type A repair. Three patients $(4.3 \%)$ had Marfan syndrome. The mean duration from dissection onset to intervention was 22.7 months. Table 1 summarizes the preoperative characteristics of the entire cohort and subgroup and Table E1 summarizes the preoperative characteristics of the entire cohort and stratifies the type of procedure and TFT.

\section{Procedure Details and Postoperative Outcomes}

Full coverage of DTA with stent graft was performed in 48 patients $(68.6 \%)$. Twenty-nine patients underwent TEVAR (TEVAR group) and the other 41 patients underwent TEVAR and additional FLP (FLP group) (Figure 1 and Table 2). The mean follow-up and imaging follow-up duration were 26.1 and 16.5 months, respectively. There was no in-hospital mortality. One patient (1.4\%) died after discharge due to intraventricular hemorrhage not associated with the procedure. No death was directly due 
TABLE 1. Baseline characteristics

\begin{tabular}{|c|c|c|c|c|}
\hline Baseline characteristics & $\begin{array}{l}\text { Entire cohort } \\
\quad(\mathbf{N}=\mathbf{7 0})\end{array}$ & $\begin{array}{c}\text { Subgroup without volumetric } \\
\text { analysis }(n=24)\end{array}$ & $\begin{array}{l}\text { Subgroup with volumetric } \\
\text { analysis }(\mathrm{n}=46)\end{array}$ & $P$ value* \\
\hline Age (y) & $\begin{array}{c}54.8 \pm 11.6 \\
55.0(46.0-64.0)\end{array}$ & $\begin{array}{c}58.5 \pm 13.6 \\
56.0(44.5-72.8)\end{array}$ & $\begin{array}{c}52.9 \pm 10.1 \\
51.5(46.8-62.3)\end{array}$ & .087 \\
\hline Male sex & $55(78.6)$ & $18(75.0)$ & $37(80.4)$ & $.599 \dagger$ \\
\hline Hypertension & $58(82.9)$ & $22(91.7)$ & $36(78.3)$ & .197 \\
\hline Diabetes mellitus & $6(8.6)$ & $2(8.3)$ & $4(8.7)$ & $>.999$ \\
\hline Chronic renal failure & $2(2.9)$ & $0(0)$ & $2(4.3)$ & .543 \\
\hline Smoking & $34(48.6)$ & $9(37.5)$ & $25(54.3)$ & $.181 \dagger$ \\
\hline Coronary artery occlusive disease & $4(5.7)$ & $1(4.2)$ & $3(6.5)$ & $.687 \dagger$ \\
\hline Chronic obstructive pulmonary disease & $2(2.9)$ & $0(0)$ & $2(4.3)$ & $.300 \dagger$ \\
\hline Marfan syndrome & $3(4.3)$ & $1(4.2)$ & $2(4.3)$ & $.972 \dagger$ \\
\hline Previous aortic surgery & $36(51.4)$ & $14(58.3)$ & $22(47.8)$ & .457 \\
\hline Duration from dissection to intervention (mo) & $\begin{array}{c}22.7 \pm 27.9 \\
11.6(4.0-31.5)\end{array}$ & $\begin{array}{c}22.1 \pm 27.4 \\
12.4(3.3-28.8)\end{array}$ & $\begin{array}{c}23.1 \pm 28.5 \\
10.6(4.1-32.3)\end{array}$ & $.357 \ddagger$ \\
\hline
\end{tabular}

Values are expressed as mean \pm standard deviation and median (interquartile range) for continuous data or $\mathrm{n}(\%)$ for categorical data. $* P$ value was calculated comparing without volumetric analysis versus with volumetric analysis. $\dagger P$ value was calculated using Pearson $\chi^{2}$ test. $\ddagger P$ value was calculated using Mann-Whitney $U$ test.

to aortic complications. One patient $(1.4 \%)$ had spinal cord ischemia and completely recovered without any sequelae. One patient $(1.4 \%)$ had upper limb motor weakness after FLP, which was due to ischemic stroke observed on brain magnetic resonance imaging. One patient $(1.4 \%)$ underwent OAR after TEVAR due to a continuously enlarging dissecting aneurysm. One patient had iatrogenic type A aortic dissection after TEVAR. However, FL thrombosis in the ascending aorta was demonstrated on CT scan and no emergency operation or further intervention was needed. There was no renal failure or any other major complication. TFT was achieved in 61 patients $(87.1 \%)$ (Table 3). Tables 2 and 3 summarize the procedure details and the operative outcome of the entire cohort and subgroup. Table E2 summarizes the procedure details and operative outcome of the entire cohort and stratifies the type of procedure and TFT.

\section{Abdominal Aorta Status}

Of the entire cohort, 17 patients $(24.3 \%)$ demonstrated abdominal expansion status on the latest CT scan. Although TFT was achieved, 15 patients $(24.6 \%)$ demonstrated

TABLE 2. Procedure-related details and follow-up data

\begin{tabular}{|c|c|c|c|c|}
\hline Procedure details & $\begin{array}{l}\text { Entire cohort } \\
\qquad(N=70)\end{array}$ & $\begin{array}{l}\text { Subgroup without volumetric } \\
\text { analysis }(n=24)\end{array}$ & $\begin{array}{c}\text { Subgroup with volumetric } \\
\text { analysis }(n=46)\end{array}$ & $P$ value* \\
\hline Full coverage of descending thoracic aorta & $48(68.6)$ & $16(66.7)$ & $32(69.6)$ & $.804 \dagger$ \\
\hline \multicolumn{5}{|l|}{ Proximal landing zone } \\
\hline Zone 0 & $3(4.3)$ & $1(4.2)$ & $2(4.3)$ & $>.999$ \\
\hline Zone 1 & $9(12.9)$ & $0(0)$ & $9(19.6)$ & .023 \\
\hline Zone 2 & $32(45.7)$ & $14(58.3)$ & $18(39.1)$ & $.126 \dagger$ \\
\hline Zone 3 & $18(25.7)$ & $5(20.8)$ & $13(28.3)$ & $.500^{\dagger}$ \\
\hline Zone 4 & $8(11.4)$ & $4(16.7)$ & $4(8.7)$ & .432 \\
\hline \multirow[t]{2}{*}{ Follow-up duration (mo) } & $26.1 \pm 12.3$ & $22.0 \pm 12.6$ & $28.3 \pm 11.8$ & \multirow[t]{2}{*}{$.054 \ddagger$} \\
\hline & $25.8(15.8-38.7)$ & $19.5(10.1-34.5)$ & $26.8(18.0-39.2)$ & \\
\hline \multirow[t]{2}{*}{ Imaging follow-up duration (mo) } & $16.5 \pm 10.6$ & $12.2 \pm 8.6$ & $18.8 \pm 10.9$ & \multirow[t]{2}{*}{.013} \\
\hline & $16.3(8.1-23.2)$ & $11.5(3.9-21.7)$ & $17.9(10.0-25.4)$ & \\
\hline \multirow[t]{2}{*}{ Imaging follow-up (n) } & $4.0 \pm 1.9$ & $2.5 \pm 1.1$ & $4.8 \pm 1.8$ & \multirow[t]{2}{*}{$<.001 \ddagger$} \\
\hline & $4.0(2.8-5.0)$ & $2.0(2.0-3.0)$ & $4.5(3.0-6.0)$ & \\
\hline False lumen procedure & $41(58.6)$ & $10(41.7)$ & $31(67.4)$ & $.038 \dagger$ \\
\hline $\begin{array}{l}\text { Simultaneous thoracic endovascular aortic } \\
\text { repair }+ \text { false lumen procedure }\end{array}$ & $16(22.9)$ & $8(33.3)$ & $8(17.4)$ & $.132 \dagger$ \\
\hline
\end{tabular}

Values are presented as mean \pm standard deviation and median (interquartile range) for continuous data or $\mathrm{n}(\%)$ for categorical data. $* P$ value was calculated comparing without volumetric analysis versus with volumetric analysis. $\dagger P$ value was calculated using Pearson $\chi^{2}$ test. $\ddagger P$ value was calculated using Mann-Whitney $U$ test. 
TABLE 3. Operative outcome

\begin{tabular}{|c|c|c|c|c|}
\hline Operative outcome & $\begin{array}{l}\text { Entire cohort } \\
\qquad(N=70)\end{array}$ & $\begin{array}{l}\text { Subgroup without } \\
\text { volumetric analysis } \\
(\mathbf{n}=\mathbf{2 4})\end{array}$ & $\begin{array}{c}\text { Subgroup with } \\
\text { volumetric analysis } \\
(\mathrm{n}=\mathbf{4 6})\end{array}$ & $P$ value* \\
\hline In-hospital mortality & $0(0.0)$ & $0(0)$ & $0(0)$ & \\
\hline Overall mortality & $1(1.4)$ & $1(4.2)$ & $0(0)$ & .343 \\
\hline Permanent paraplegia & $0(0.0)$ & $0(0)$ & $0(0)$ & \\
\hline Cerebral spinal fluid complication & $8(11.4)$ & $3(12.5)$ & $5(10.9)$ & $>.999$ \\
\hline Ischemic stroke & $1(1.4)$ & $0(0)$ & $1(2.2)$ & $>.999$ \\
\hline Open conversion & $1(1.4)$ & $1(4.2)$ & $0(0)$ & .343 \\
\hline Iatrogenic type A dissection & $1(1.4)$ & $0(0)$ & $1(2.2)$ & $>.999$ \\
\hline $\begin{array}{l}\text { Abdominal aorta status } \\
\text { Expansion status } \ddagger \\
\text { Stable status }\end{array}$ & $\begin{array}{l}17(24.3) \\
53(75.7)\end{array}$ & $\begin{array}{r}5(20.8) \\
19(79.2)\end{array}$ & $\begin{array}{l}12(26.1) \\
34(73.9)\end{array}$ & $.627 \dagger$ \\
\hline Thoracic false lumen thrombosis & $61(87.1)$ & $20(83.3)$ & $41(89.1)$ & .481 \\
\hline Abdominal false lumen thrombosis & $8(11.4)$ & $3(12.5)$ & $5(10.9)$ & $>.999 \dagger$ \\
\hline
\end{tabular}

Values are presented as $\mathrm{n}(\%)$. $* P$ value was calculated comparing without volumetric analysis versus with volumetric analysis. $\dagger P$ value was calculated using Pearson $\chi^{2}$ test. $\ddagger$ Defined as $>5 \mathrm{~mm}$ increased at 1 level at least.

abdominal expansion status. There was no difference regarding the frequency of expansion status stratified by TFT and FLP (Figure 2). The most prevalent site of expansion status was the infrarenal level. Celiac level was the most prevalent site of expansion status in the FLP group (Figure 3).

\section{Volume Analysis}

Abdominal aortic volume was measured to evaluate the overall fate of the abdominal aortic dissection in the subgroup of patients $(n=46)$ with 3 or more postoperative measurements of abdominal aortic volume. Baseline characteristics, procedure-related details, and operative outcomes of this subgroup were not significantly different

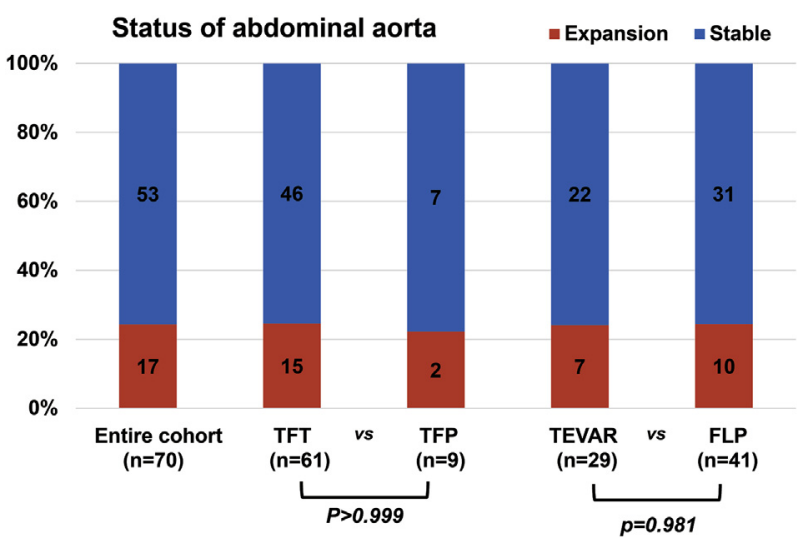

FIGURE 2. The expansion ( $>5 \mathrm{~mm}$ increased at 1 level at least; red bars) or stable (blue bars) status of abdominal aortic diameter. The numbers on the bars indicate the number of patients. TFT, Thoracic false lumen thrombosis; TFP, thoracic false lumen partial thrombosis; TEVAR, thoracic endovascular aortic repair; FLP, false lumen procedure. compared with the entire cohort (Tables 1-3). The mean total abdominal aortic volume at preoperative measurement was significantly smaller than at postoperative measurement $\left(68.3 \pm 25.7 \mathrm{~cm}^{3}\right.$ [median, $61.9 \mathrm{~cm}^{3}$; IQR, 48.2-81.5 $\left.\mathrm{cm}^{3}\right]$ vs $72.5 \pm 29.3 \mathrm{~cm}^{3}$ [median, $64.9 \mathrm{~cm}^{3}$; IQR, 52.2-90.1 $\mathrm{cm}^{3}$ ]; $\left.P=.001\right)$. The $\mathrm{TL}$ and $\mathrm{FL}$ abdominal aortic volumes were both growing over time on LMM analysis (B \pm standard error, $0.248 \pm 0.041 \mathrm{~cm}^{3} / \mathrm{mo}[P<.001]$ and $0.341 \pm 0.156 \mathrm{~cm}^{3} / \mathrm{mo}[P=.033]$, respectively) (Table 4 and Figures 4 and 5). Thus, the total abdominal aortic volume was growing over time on LMM analysis $\left(0.603 \pm 0.158 \mathrm{~cm}^{3} / \mathrm{mo}[P<.001]\right)$ (Table 5 and Figure 6). The number of large intima tears was the only significant predictor associated with growth of FL volume and there was no statistically significant factor associated with TL volume change (Table 4). The number of large intima tears and the presence of small intima tears were significant predictors associated with total abdominal aortic volume change (Table 5).

The multivariable LMM for total abdominal aortic volume demonstrated that the number of large intima tears and the presence of small intima tears were the independent predictors for enlarging total abdominal aortic volume $\left(0.184 \pm 0.080 \mathrm{~cm}^{3} / \mathrm{mo} \quad[P=.023]\right.$ and $0.306 \pm 0.136 \mathrm{~cm}^{3} / \mathrm{mo}[P=.027]$, respectively) (Table 6).

\section{DISCUSSION}

At our institution, we attempted to deploy the stent graft for as long as possible (full coverage of DTA in 48 patients [68.6\%]) and FLP was performed around the distal stent area in 41 patients $(58.6 \%)$. The FLP materials blocked FL backflow and favored thoracic aorta FL thrombosis. ${ }^{11}$ 


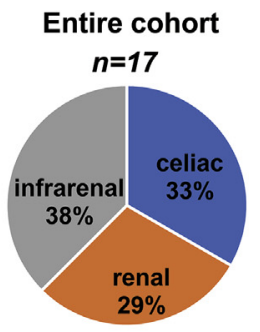

A - celiac renal infrarenal

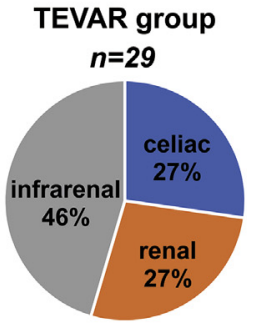

D = celiac renal infrarenal

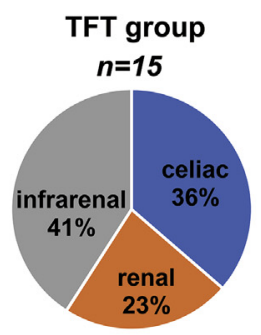

B - celiac - renal $\square$ infrarenal

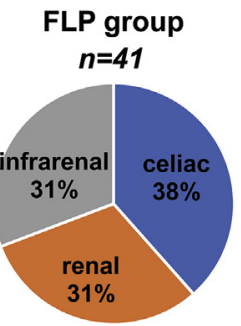

E celiac

- renal infrarenal

FIGURE 3. The site of abdominal aortic diameter expansion. A, Entire cohort. B, Thoracic false lumen thrombosis (TFT) group. C, Thoracic false lumen partial thrombosis (TFP) group. D, Thoracic endovascular aortic repair (TEVAR) group. E, False lumen procedure (FLP) group.

However, regarding the aortic diameter, the expandable TEVAR stent graft enlarged the TL, and the FLP materials that permanently occupied the space possibly hindered FL shrinkage to some degree. Therefore, the most prevalent site of abdominal aortic diameter expansion was at the celiac level in the FLP group and the infrarenal level was the most prevalent site in the other groups (Figure 3). Another possible reason is that the infrarenal aorta is vulnerable to enlargement because its histologic structure and mechanical characteristics differ from other areas. ${ }^{12}$

The authors also conducted LMM analysis for abdominal aortic diameter at 3 levels (celiac, renal, and infrarenal).
The abdominal aortic diameter of each level increased significantly over time. However, there were no significant anatomic or procedure factors associated with diameter change. Although the aortic diameter is easily accessible and clinically useful, the diameter at a specific site cannot reflect the overall fate of the abdominal aorta or the extent of abdominal aortic remodeling. Furthermore, it is technically difficult to measure the diameter of TL and FL because the shape of TLs and FLs is irregular and varying. Indeed, in our study population, the diameter of FL occasionally seemed to be constant even if the FL volume was decreasing significantly. Lastly, the number

TABLE 4. Subgroup analysis $(n=46)$ using univariable linear mixed model for true lumen and false lumen abdominal aortic volume

\begin{tabular}{|c|c|c|c|c|}
\hline \multirow[b]{2}{*}{ Anatomy and procedure factors } & \multicolumn{2}{|c|}{$\begin{array}{c}\text { True lumen volume } \\
\left(\mathrm{cm}^{3} / \mathrm{mo}\right) \\
\end{array}$} & \multicolumn{2}{|c|}{$\begin{array}{l}\text { False lumen volume } \\
\left(\mathrm{cm}^{3} / \mathrm{mo}\right)\end{array}$} \\
\hline & B \pm standard error & $P$ value* & B \pm standard error & $P$ value* \\
\hline Time from procedure (mo) & $0.248 \pm 0.041$ & $<.001$ & $0.341 \pm 0.156$ & .033 \\
\hline False lumen procedure & $-0.009 \pm 0.052$ & .870 & $-0.099 \pm 0.117$ & .398 \\
\hline Full coverage of descending thoracic aorta & $-0.020 \pm 0.070$ & .780 & $-0.071 \pm 0.168$ & .672 \\
\hline Thoracic false lumen thrombosis & $-0.058 \pm 0.138$ & .678 & $-0.118 \pm 0.135$ & .385 \\
\hline Large intima tears (n) $\dagger$ & $-0.029 \pm 0.033$ & .376 & $0.211 \pm 0.079$ & .009 \\
\hline Visceral branches from false lumen (n) & $-0.044 \pm 0.033$ & .187 & $0.099 \pm 0.093$ & .290 \\
\hline Small intima tears (n) $\dagger$ & $0.010 \pm 0.016$ & .553 & $0.049 \pm 0.039$ & .213 \\
\hline Small intima tears (presence or not) & $0.104 \pm 0.058$ & .078 & $0.200 \pm 0.143$ & .166 \\
\hline
\end{tabular}

* $P$ value was calculated on interaction between variables $\times$ time from procedure (month). $\dagger$ Large intima tear was defined as intima tear observed at least 2 consecutive axial cuts on computed tomography scan. Small intima tear was defined as intima tear observed $<2$ consecutive axial cuts on computed tomography scan. 


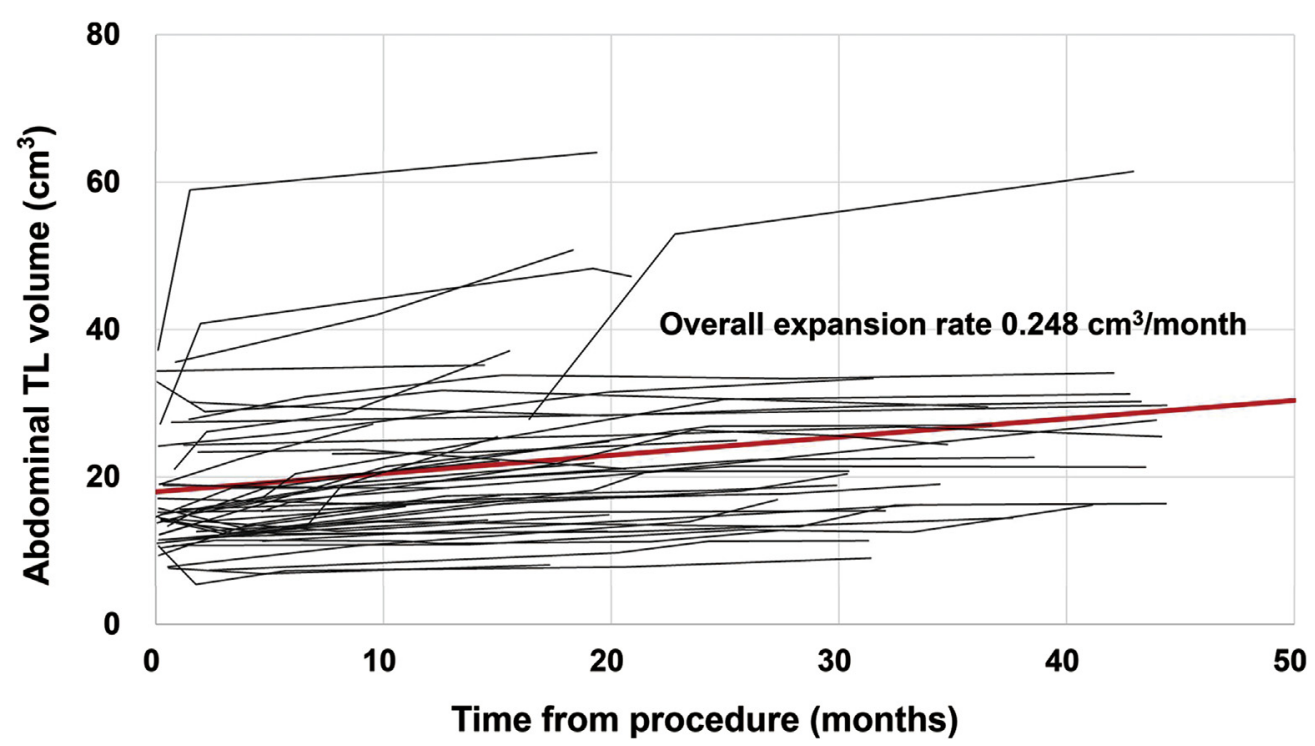

FIGURE 4. Spaghetti plot showing changes of abdominal true lumen $(T L)$ volume over time in individual patients $(\mathrm{n}=46)$. Red line indicates overall expansion rate of abdominal TL volume calculated on the univariable linear mixed model.

of postoperative CT scans was heterogenous in the study population. Thus, for precise and comprehensive analysis, we measured abdominal aortic volume in the subgroup of patients who had more than 2 postoperative CT scans and analyzed total, TL, and FL abdominal aortic volumes using LMM.

The number of large intima tears was the only significant risk factor for FL volume expansion and the number of large intima tears and the presence of small intima tears were the only independent anatomy risk factors associated with enlarging total abdominal aortic volume on multivariable
LMM analysis (Tables 4 and 5). These results imply that conventional TEVAR or FLP is not a sufficient treatment strategy for patients with CDIIIb and an additional intervention seems necessary irrespective of thoracic aorta stabilization. According to in vitro and computational fluid dynamic study by Eduardo and colleagues, ${ }^{13}$ distal FL diastolic pressure with distal intima tear was higher than the pressure of model with proximal and distal intima tear. According to another in vitro flow-dynamics study, proximal and distal intima tears seemed to act as entries and exits into the FL suggesting that flow enters and exits

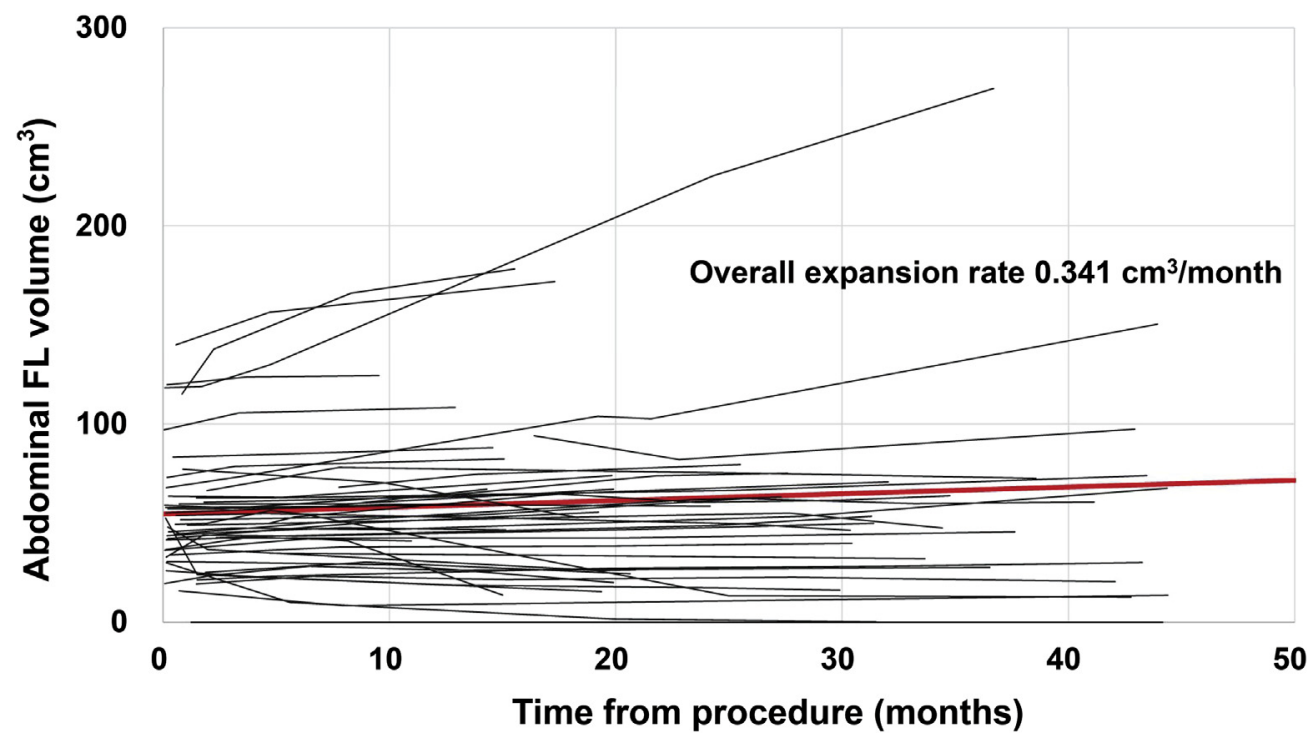

FIGURE 5. Spaghetti plot showing changes of abdominal false lumen $(F L)$ volume over time in individual patients $(\mathrm{n}=46)$. Red line indicates overall expansion rate of abdominal FL volume calculated on the univariable linear mixed model. 
TABLE 5. Subgroup analysis $(n=46)$ using univariable linear mixed model for abdominal aortic volume (centimeters $3 /$ month)

\begin{tabular}{lcc}
\hline \multicolumn{1}{c}{ Anatomy and procedure factors } & $\begin{array}{c}\text { B } \pm \text { standard } \\
\text { error }\end{array}$ & $\boldsymbol{P}$ value* \\
\hline Time from procedure $(\mathrm{mo})$ & $0.603 \pm 0.158$ & $<.001$ \\
\hline False lumen procedure & $-0.127 \pm 0.104$ & .227 \\
\hline Full coverage of descending thoracic aorta & $-0.146 \pm 0.155$ & .349 \\
\hline Thoracic false lumen thrombosis & $-0.094 \pm 0.120$ & .438 \\
\hline Large intima tears $(\mathrm{n}) \dagger$ & $0.223 \pm 0.074$ & .003 \\
\hline Visceral branches from false lumen (n) & $0.048 \pm 0.090$ & .597 \\
\hline Small intima tears $(\mathrm{n}) \dagger$ & $0.066 \pm 0.037$ & .139 \\
\hline Small intima tears $($ presence or not) & $0.359 \pm 0.133$ & .008 \\
\hline $\begin{array}{l}* P \text { value } \text { was calculated on interaction between variables } \times \text { time from procedure } \\
\text { (month). } \dagger \text { Large intima tear was defined as intima tear observed at least } 2 \text { consecutive }\end{array}$ \\
$\begin{array}{l}\text { axial cuts on computed tomography scan. Small intima tear was defined as intima tear } \\
\text { observed }<2 \text { consecutive axial cuts on computed tomography scan. }\end{array}$
\end{tabular}

the FL through all tears simultaneously during systole and diastole. ${ }^{14}$ Although TEVAR stent grafts block the primary tears, the flow dynamics of residual abdominal aortic dissection might be unchanged before and after TEVAR. Therefore, the abdominal aorta would keep enlarging unless intima tears in the abdominal aorta are blocked, regardless of thoracic aorta FL thrombosis and the type of procedure.

Of 70 patients, 3 patients underwent additional FLP on the abdominal aorta after TEVAR or FLP. Abdominal FLPs required the insertion of materials (eg, vascular plugs and coils) into the FL of the abdominal aorta to block FL flow. All of these patients demonstrated abdominal aorta shrinkage. Two of 3 patients demonstrated FL thrombosis down to the infrarenal abdominal aorta and there was no morbidity or mortality in these patients. This finding seems
TABLE 6. Subgroup analysis $(n=46)$ using multivariable linear mixed model for abdominal aortic volume (centimeter ${ }^{3} /$ month $^{2}$

\begin{tabular}{lcc}
\hline \multicolumn{1}{c}{ Anatomy and procedure factors } & $\mathbf{B} \pm$ standard error & $\boldsymbol{P}$ value* \\
\hline Large intima tears $(\mathrm{n}) \dagger$ & $0.184 \pm 0.080$ & .023 \\
Small intima tears (presence or not) $\dagger$ & $0.306 \pm 0.136$ & .027 \\
\hline$* P$ value was calculated on interaction between variables $\times$ time from procedure \\
$\begin{array}{l}\text { (month). } \dagger \text { Large intima tear was defined as intima tear observed at least } 2 \text { consecutive } \\
\text { axial cuts on computed tomography scan. Small intima tear was defined as intima tear } \\
\text { observed }>2 \text { consecutive axial cuts on computed tomography scan. }\end{array}$
\end{tabular}

important because the whole aorta may be stabilized via endovascular approaches. To date, the outcome of aortic remodeling with endovascular treatment in patients with CDIIIb is inferior to that of OAR. However, TEVAR is still widely used in these patients because surgical morbidity and mortality are high with OAR and the short- and mid-term results of endovascular treatment are acceptable and much safer compared with OAR. With device and technical improvements, endovascular treatment in CDIIIb aneurysms, including the abdominal level seems promising.

\section{Limitations}

There were several limitations in this study. First, it was retrospective study and the cohort was heterogenous. Moreover, the study sample was small and the follow-up duration was relatively short (mean follow-up duration, 26.1 months). In 3 patients, abdominal FLPs were performed and may have been a confounding factor in the analysis of the entire cohort. Although statistical power was limited due to the size of sample, especially in subgroup analysis, this study demonstrated important findings regarding the fate of abdominal dissection after endovascular treatments in CDIIIb aneurysms.

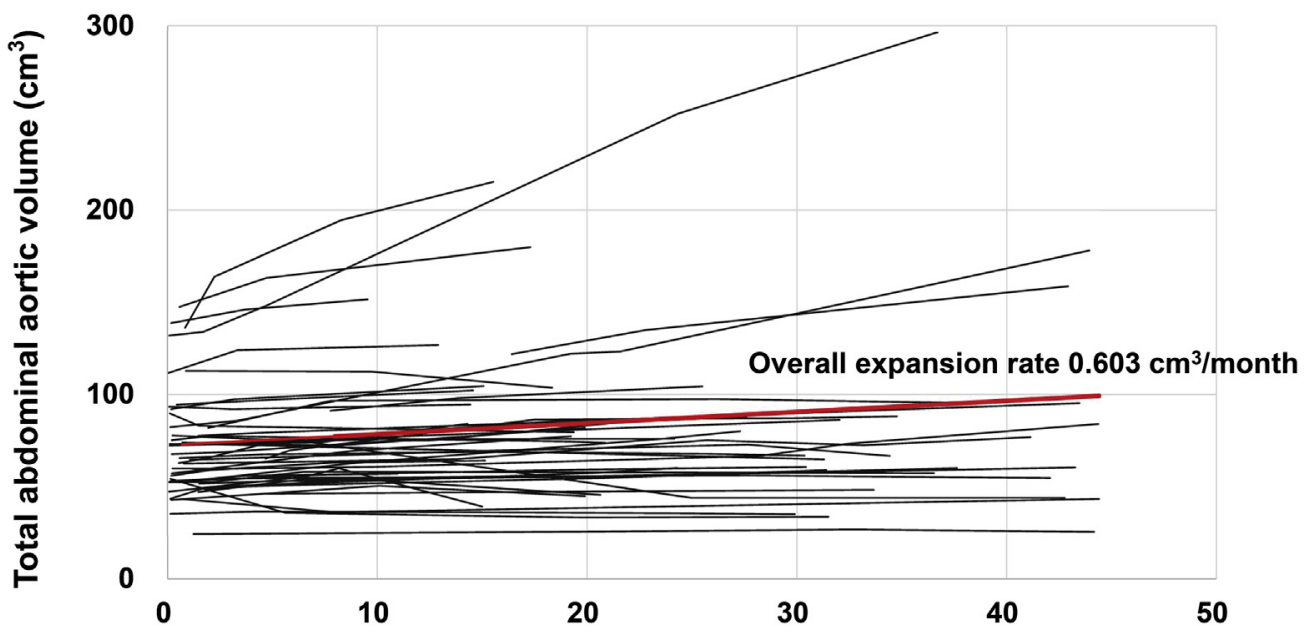

Time from procedure (months)

FIGURE 6. Spaghetti plot showing changes of total abdominal aortic volume over time in individual patients $(\mathrm{n}=46)$. Red line indicates overall expansion rate of total abdominal aortic volume calculated on univariable linear mixed model. 


\section{CONCLUSIONS}

Knowing the fate of an abdominal dissection is very important to improve the outcome of endovascular management in patients with CDIIIb. Residual abdominal aortic dissections seem unaffected by TFT or FLPs within the thoracic aorta. An enlarged abdominal aorta is frequently recognizable even after successful TEVAR or FLP in CDIIIb aneurysms. The number of large intima tears and the presence of small intima tears were the identified anatomic risk factors for abdominal aneurysm change. We suggest that abdominal aortas should be carefully evaluated and that additional procedures on the FL might be needed.

\section{Webcast}

You can watch a Webcast of this AATS meeting presentation by going to: https://aats.blob.core.windows.net/media/ 17AM/2017-05-02/RM311/05-02-17_Room311_1705_ Kim.mp4.

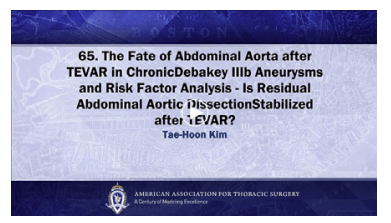

\section{Conflict of Interest Statement}

Authors have nothing to disclose with regard to commercial support.

\section{References}

1. Kolbel T, Lohrenz C, Kieback A, Diener H, Debus ES, Larena-Avellaneda A. Distal false lumen occlusion in aortic dissection with a homemade extra-large vascular plug: the candy-plug technique. J Endovasc Ther. 2013;20:484-9.

2. Fattori R, Tsai TT, Myrmel T, Evangelista A, Cooper JV, Trimarchi S, et al. Complicated acute type B dissection: is surgery still the best option? A report from the international registry of acute aortic dissection. JACC Cardiovasc Interv. 2008;1:395-402.
3. Cheng D, Martin J, Shennib H, Dunning J, Muneretto C, Schueler S, et al. Endovascular aortic repair versus open surgical repair for descending thoracic aortic disease a systematic review and meta-analysis of comparative studies. J Am Coll Cardiol. 2010;55:986-1001.

4. Hughes GC, Ganapathi AM, Keenan JE, Englum BR, Hanna JM, Schechter MA, et al. Thoracic endovascular aortic repair for chronic DeBakey IIIb aortic dissection. Ann Thorac Surg. 2014;98:2092-7; discussion 2098.

5. Eriksson MO, Steuer J, Wanhainen A, Thelin S, Eriksson LG, Nyman R. Morphologic outcome after endovascular treatment of complicated type B aortic dissection. J Vasc Interv Radiol. 2013;24:1826-33.

6. Nienaber CA, Kische S, Rousseau H, Eggebrecht H, Rehders TC, Kundt G, et al. Endovascular repair of type B aortic dissection: long-term results of the randomized investigation of stent grafts in aortic dissection trial. Circ Cardiovasc Interv. 2013:6:407-16.

7. Khoynezhad A, Toluie S, Al-Atassi T. Treatment of the chronic type B aortic dissection: the pro-endovascular argument. Semin Thorac Cardiovasc Surg. 2017;29:131-6.

8. Weber TF, Böckler D, Muller-Eschner M, Bischoff M, Kronlage M, von Tengg-Kobligk H, et al. Frequency of abdominal aortic expansion after thoracic endovascular repair of type B aortic dissection. Vascular. 2016;24: 567-79

9. Dake MD, Thompson M, van Sambeek M, Vermassen F, Morales JP, Investigators D. DISSECT: a new mnemonic-based approach to the categorization of aortic dissection. Eur J Vasc Endovasc Surg. 2013;46: 175-90.

10. Song SW, Kim TH, Lim SH, Lee KH, Yoo KJ, Cho BK. Prognostic factors for aorta remodeling after thoracic endovascular aortic repair of complicated chronic DeBakey IIIb aneurysms. J Thorac Cardiovasc Surg. 2014;148:925-32. 933e1; discussion 932-3.

11. Kim TH, Song SW, Lee KH, Baek MY, Yoo KJ. Effects of false lumen procedures on aorta remodeling of chronic DeBakey IIIb aneurysm. Ann Thorac Surg. 2016; 102:1941-7.

12. Collins MJ, Bersi M, Wilson E, Humphrey JD. Mechanical properties of suprarenal and infrarenal abdominal aorta: implications for mouse models of aneurysms. Med Eng Phys. 2011;33:1262-9.

13. Soudah E, Rudenick P, Bordone M, Bijnens B, García-Dorado D, Evangelista A, et al. Validation of numerical flow simulations against in vitro phantom measurements in different type B aortic dissection scenarios. Comput Methods Biomech Biomed Engin. 2015;18:805-15.

14. Rudenick PA, Bijnens BH, Garcia-Dorado D, Evangelista A. An in vitro phantom study on the influence of tear size and configuration on the hemodynamics of the lumina in chronic type B aortic dissections. J Vasc Surg. 2013;57:464-74.e465.

Key Words: chronic DeBakey IIIb, the fate of abdominal aortic dissection, thoracic endovascular aortic repair 
TABLE E1. Baseline characteristics stratified by false lumen procedure (FLP) and thoracic false lumen thrombosis (TFT)

\begin{tabular}{|c|c|c|c|c|c|c|}
\hline Characteristic & $\begin{array}{c}\text { Thoracic } \\
\text { endovascular } \\
\text { aortic repair } \\
(\mathbf{n}=\mathbf{2 9})\end{array}$ & $\begin{array}{c}\text { FLP } \\
(n=41)\end{array}$ & $P$ value* & $\begin{array}{c}\text { TFT } \\
(n=61)\end{array}$ & $\begin{array}{l}\text { Thoracic false } \\
\text { lumen partial } \\
\text { thrombosis } \\
(\mathbf{n}=9)\end{array}$ & $P$ value* \\
\hline Age (y) & $\begin{array}{c}55.3 \pm 12.3 \\
55.0(45.5-64.0)\end{array}$ & $\begin{array}{c}54.5 \pm 11.3 \\
53.0(47.0-64.0)\end{array}$ & .782 & $\begin{array}{c}53.9 \pm 11.4 \\
53.0(46.0-63.0)\end{array}$ & $\begin{array}{c}60.9 \pm 11.8 \\
64.0(51.5-68.5)\end{array}$ & .094 \\
\hline Male sex & $23(79.3)$ & $32(78.0)$ & $.899 \dagger$ & $50(82.0)$ & $5(55.6)$ & .091 \\
\hline Hypertension & $26(89.7)$ & $32(78.0)$ & .335 & $50(82.0)$ & $8(88.9)$ & $>.999$ \\
\hline Diabetes mellitus & $4(13.8)$ & $2(4.9)$ & .224 & $5(8.2)$ & $1(11.1)$ & .577 \\
\hline Chronic renal failure & $0(0.0)$ & $2(4.9)$ & .508 & $1(1.6)$ & $1(11.1)$ & .242 \\
\hline Smoking & $16(55.2)$ & $18(43.9)$ & $.353 \dagger$ & $32(52.5)$ & $2(22.2)$ & .152 \\
\hline Coronary artery occlusive disease & $2(6.9)$ & $2(4.9)$ & $>.999$ & $4(6.6)$ & $0(0.0)$ & $>.999$ \\
\hline Chronic obstructive pulmonary disease & $2(6.9)$ & $0(0.0)$ & .168 & $1(1.6)$ & $1(11.1)$ & .242 \\
\hline Marfan syndrome & $0(0.0)$ & $3(7.3)$ & .261 & $3(4.9)$ & $0(0.0)$ & $>.999$ \\
\hline Previous aortic surgery & $15(51.7)$ & $21(51.2)$ & $.967 \dagger$ & $30(49.2)$ & $6(66.7)$ & .479 \\
\hline
\end{tabular}

Values are presented as mean \pm standard deviation and median (interquartile range) for continuous data or $\mathrm{n}(\%)$ for categorical data. $* P$ value was calculated using independent $t$ test and Fisher exact test. $\dagger P$ value was calculated using Pearson $\chi^{2}$ test.

TABLE E2. Operative outcome and procedural related details stratified by false lumen procedure (FLP) and thoracic false lumen thrombosis (TFT)

\begin{tabular}{|c|c|c|c|c|c|c|}
\hline Operative outcome & $\begin{array}{l}\text { Thoracic endovascular } \\
\text { aortic repair }(n=29)\end{array}$ & $\begin{array}{c}\text { FLP } \\
(n=41)\end{array}$ & $P$ value* & $\begin{array}{c}\text { TFT } \\
(\mathbf{n}=61)\end{array}$ & $\begin{array}{l}\text { Thoracic false lumen } \\
\text { partial thrombosis } \\
\qquad(\mathbf{n}=9)\end{array}$ & $P$ value* \\
\hline In-hospital mortality & $0(0.0)$ & $0(0.0)$ & & $0(0.0)$ & $0(0.0)$ & \\
\hline Overall mortality & $0(0.0)$ & $1(2.4)$ & $>.999$ & $1(1.6)$ & $0(0.0)$ & $>.999$ \\
\hline Permanent paraplegia & $0(0.0)$ & $0(0.0)$ & & $0(0.0)$ & $0(0.0)$ & \\
\hline Cerebral spinal fluid complication & $3(10.3)$ & $5(12.2)$ & $>.999$ & $7(11.5)$ & $1(11.1)$ & $>.999$ \\
\hline Ischemic stroke & $0(0.0)$ & $1(2.4)$ & $>.999$ & $1(1.6)$ & $0(0.0)$ & $>.999$ \\
\hline Open conversion & $1(0.0)$ & $0(0.0)$ & .414 & $1(1.6)$ & $0(0.0)$ & $>.999$ \\
\hline Iatrogenic type A dissection & $0(0.0)$ & $1(2.4)$ & $>.999$ & $0(0.0)$ & $1(11.1)$ & .129 \\
\hline Full coverage of descending thoracic aorta & $13(44.8)$ & $35(85.4)$ & $<.001 \dagger$ & $40(65.6)$ & $8(88.9)$ & .255 \\
\hline Abdominal aorta status & & & $.981 \dagger$ & & & $>.999$ \\
\hline Expansion (>5 mm) & $7(24.1)$ & $10(24.4)$ & & $15(24.6)$ & $2(22.2)$ & \\
\hline Stable $(<5 \mathrm{~mm})$ & $22(75.9)$ & $31(75.6)$ & & $46(75.4)$ & $7(77.8)$ & \\
\hline TFT & $26(89.7)$ & $35(85.4)$ & .726 & & & \\
\hline FLP & & & & $35(57.4)$ & $6(66.7)$ & .726 \\
\hline
\end{tabular}

Values are presented as $\mathrm{n}(\%)$. ${ }^{*} P$ value was calculated using independent $t$ test and Fisher exact test. $\dagger P$ value was calculated using Pearson $\chi^{2}$ test. 